\title{
Active opening out of the urethra and the Valentini-Besson-Nelson mathematical model: response to comment by Petros and Bush
}

\author{
Françoise A. Valentini • Pierre P. Nelson
}

Published online: 14 June 2013

(C) The International Urogynecological Association 2013

Dear Editor,

We thank Dr. Petros and Dr. Bush for their interest in our paper [1] and the VBN model and would like to offer the following comments:

1. Dr Petros and Dr Bush [2] show a deep understanding of the Valentini-Besson-Nelson (VBN) mathematical micturition model. Active opening of the urethra is a reality but it is not included in the current version of the VBN model.

2. Our aim is to try to include that phenomenon in the next version of the model. We think that active opening of the urethra could probably be simulated by a negative compression of the urethra. That is the first test to do.

3 . We think that active opening cannot explain the abnormal decrease of the maximum flow rate induced by the catheter. The observed effect is similar to an increase of the urethral obstruction; active opening would lead to a decrease of the urethral obstruction and thus an increased maximum flow rate.

4. We have just begun the study of the high flow rate-low detrusor pressure voidings which are frequently observed in women. The first result is that voiding conditions need to introduce an enlarged urethra in the model. Active opening is probably the cause of such enlargement.

\section{References}

1. Valentini FA, Robain G, Hennebelle DS, Nelson PP (2013) Decreased maximum flow rate during intubated flow is not only due to urethral catheter in situ. Int Urogynecol J 24:461-467

2. Petros PEP, Bush M (2013) Active opening out of the urethra questions the basis of the Valentini-Besson-Nelson mathematical model. Int Urogynecol J. doi:10.1007/s00192-013-2128-5 